\title{
Effect of 24\% EDTA root conditioning on the outcome of modified coronally advanced tunnel technique with subepithelial connective tissue graft for the treatment of multiple gingival recessions: a randomized clinical trial
}

\author{
Bartłomiej Górski ${ }^{1}$ [D $\cdot$ Marcin Szerszeń ${ }^{2} \cdot$ Tomasz Kaczyński $^{1}$
}

Received: 1 July 2021 / Accepted: 16 August 2021 / Published online: 24 August 2021

(c) The Author(s) 2021

\begin{abstract}
Objectives To investigate effects of root conditioning with $24 \%$ ethylenediaminetetraacetic acid (EDTA) on the 12 -month outcomes after treatment of multiple gingival recessions (GR) with modified coronally advanced tunnel (MCAT) and subepithelial connective tissue graft (SCTG).

Materials and methods Twenty patients with 142 GR were treated (72 test sites: SCTG + EDTA and 70 control sites: SCTG). Average and complete root coverage (ARC, CRC), gain in keratinized tissue width (KTW), gain in gingival thickness (GT), root esthetic coverage score (RES), and patient-reported outcome measures (PROMs) were evaluated at 12 months post-operatively.

Results Differences between pre- and post-operative values were statistically significant only within but not between treatment modalities. At 12 months, ARC was $86.0 \%$ for SCTG + EDTA-treated and 84.6 for SCTG-treated defects $(p=0.6636)$. CRC was observed in $90.2 \%$ (tests) and $91.4 \%$ (controls) of all cases $(p=0.9903)$. Professional assessment of esthetic outcomes using RES showed highly positive results reaching the value of 8.9 in case of test sites and 8.7 for control sites $(p=0.3358)$. Severity of pain and swelling did not differ between sites, regardless of whether EDTA was used.

Conclusions Test and control sites presented similarly positive outcomes related to root coverage, periodontal and esthetic parameters, and patient satisfaction and self-reported morbidity with no statistical differences between them 12 months after surgery. No significant differences in evaluated variables were observed between sites treated with and without 24\% EDTA. Clinical relevance

Considering the limitations of the present study, the use of 24\% EDTA for root conditioning did not improve 12-month outcomes after treatment of multiple RT1 and RT2 gingival recessions with MCAT and SCTG.

Trial registration

ClinicalTrials.gov identifier: NCT03354104
\end{abstract}

Keywords Esthetics $\cdot$ Ethylenediaminetetraacetic acid (EDTA) - Modified coronally advanced tunnel technique $\cdot$ Multiple gingival recessions $\cdot$ Subepithelial connective tissue graft

Bartłomiej Górski

bartek_g3@tlen.pl

1 Department of Periodontology and Oral Mucosa Diseases, Medical University of Warsaw, Stanisława Binieckiego St 6, 02-097 Warsaw, Poland

2 Department of Dental Prosthetics, Medical University of Warsaw, Stanisława Binieckiego St 6, 02-097 Warsaw, Poland

\section{Introduction}

Gingival recession (GR) is an apical displacement of the gingival margin with the concomitant exposure of a portion of the root cementum. It is often associated with root caries, esthetic, and hypersensitivity concerns, which constitute significant therapeutic problems for patients. If left untreated, the progression of GR was estimated to be $0.4 \mathrm{~mm}$ over an average follow-up of 4 years [1]. GR affects population with both poor and high oral hygiene [2]. Quite recently, 
the prevalence of GR was reported in $91.6 \%$ of evaluated subjects and decreased to $70.7 \%$ when only the esthetic zone was considered [3].

A plethora of techniques and different flap designs have been developed for the surgical treatment of GR. Zabalegui et al. [4] described the tunnel approach that preserved the integrity of the papillae and did not require vertical releasing incisions when obtaining root coverage, which may increase coronal blood supply. Tunnel approach showed great potential in correcting GR [5]. Distinct modifications to the original tunnel technique have been described over time by several authors to improve clinical outcomes [6-8]. Although the efficacy of the tunnel technique was dependent on the application of subepithelial connective tissue graft (SCTG), which was regarded as the gold standard [9], attempts have been made to search for materials alternative to SCTG, such as collagen porcine dermal matrix [10], enamel matrix derivatives [11], and concentrated growth factors [12]. In order to achieve good esthetic results, the understanding how to apply scientific evidence for a given case is crucial [13]. Lately, Aroca et al. [14] proposed site-specific, selective use of SCTG in an attempt to reduce the amount of connective tissue harvested from the palate. In a recent systematic review and meta-analysis, the extreme efficacy of modified coronally advanced tunnel technique (MCAT) in treating multiple GR defects was confirmed [15]. Average root coverage (ARC) of $87.87 \%( \pm 16.45)$ and complete root coverage (CRC) of $57.46 \%$ were calculated. However, there has recently been an emphasis on alignment between professional (surrogate) end points and patient-centered outcomes (true end points) for the evaluation of root coverage procedures [16].

Exposed root surfaces can sometimes display a hypermineralized layer of cementum and endotoxin contamination; hence, mechanical and chemical preparation of the exposed root was pinpointed to influence the treatment outcome of root coverage procedures [17]. The aims of mechanical preparation were to remove demineralization areas and caries, to smooth out any irregularities, and to reduce pronounced root convexity [18]. On the other hand, the use of chemical agents has been suggested for decontaminating of the root surface area, removing the smear layer created by root instrumentation, and enhancing the attachment of the connective tissue by the exposure of collagen fibers and amount of patent dentinal tubules of the root surface [19, 20]. Different root modifiers have been proposed and the most commonly used chemical agents were the following: ctric acid, ethylenediaminetetraacetic acid (EDTA), tetracycline, doxycycline, fibronectin, and fibrin glues [21]. Owing to its quick and easy handling, EDTA became particularly popular among dental practitioners. Nevertheless, evidence supporting its clinical use in periodontal plastic surgery remains scarce and inconsistent [12, 22, 23]. Critical analysis of the available data constitutes the main tool in the decision-making process, but based on the available data, it is not possible to clearly elucidate about the use of EDTA in root coverage procedures [24].

Despite several clinical trials that tested the effectiveness and predictability of MCAT for the correction of multiple gingival recessions in distinct clinical settings, the effectiveness of 24\% EDTA when combined with MCAT+SCTG has not yet been determined. Therefore, this randomized clinical trial aimed to study the impact of EDTA root conditioning on clinical outcomes after surgical treatment of multiple gingival recessions with MCAT+SCTG. Another goal was to assess root coverage esthetic score (RES) for professional esthetic evaluation and to analyze patient-reported outcome measures (PROMs).

\section{Materials and methods}

\section{Study design}

This study was a single-center, double-blinded, splitmouth, randomized controlled clinical trial including twenty patients (11 women and 9 men, aged 21-36; mean age $28.87 \pm 4.46$ years) who were recruited among patients referred to the Department of Periodontology and Oral Mucosa Diseases of Medical University of Warsaw between January 2019 and April 2020 (Fig. 1). The study was carried out in accordance with the Helsinki Declaration of 1975, as revised in Tokyo in 2004 after approval of the study design by the Bioethics Committee of Medical University of Warsaw (KB/208/2017; ClinicalTrials.gov ID: NCT03354104).

\section{Sample size calculation}

Taking into account that percentage of root coverage was the primary objective and based on the data indicating that standard deviation (SD) of the differences in the paired measurements would not surpass $30 \%$, the sample size for paired continuous data was calculated to be 18 subjects per treatment group [25]. This would provide $80 \%$ power to disclose a true difference of $20 \%$ points between test and control. However, considering that some patients might be lost during follow-up, 20 patients were recruited.

\section{Investigator calibration}

Six non-study patients with at least two contralateral teeth with gingival recessions were enrolled for the calibration exercise. The designated examiner (DP) made clinical measurements twice at an interval of $24 \mathrm{~h}$ in 24 defects. Calibration was accepted when $\geq 90 \%$ of the recordings were 
Fig. 1 Consort diagram showing the study design

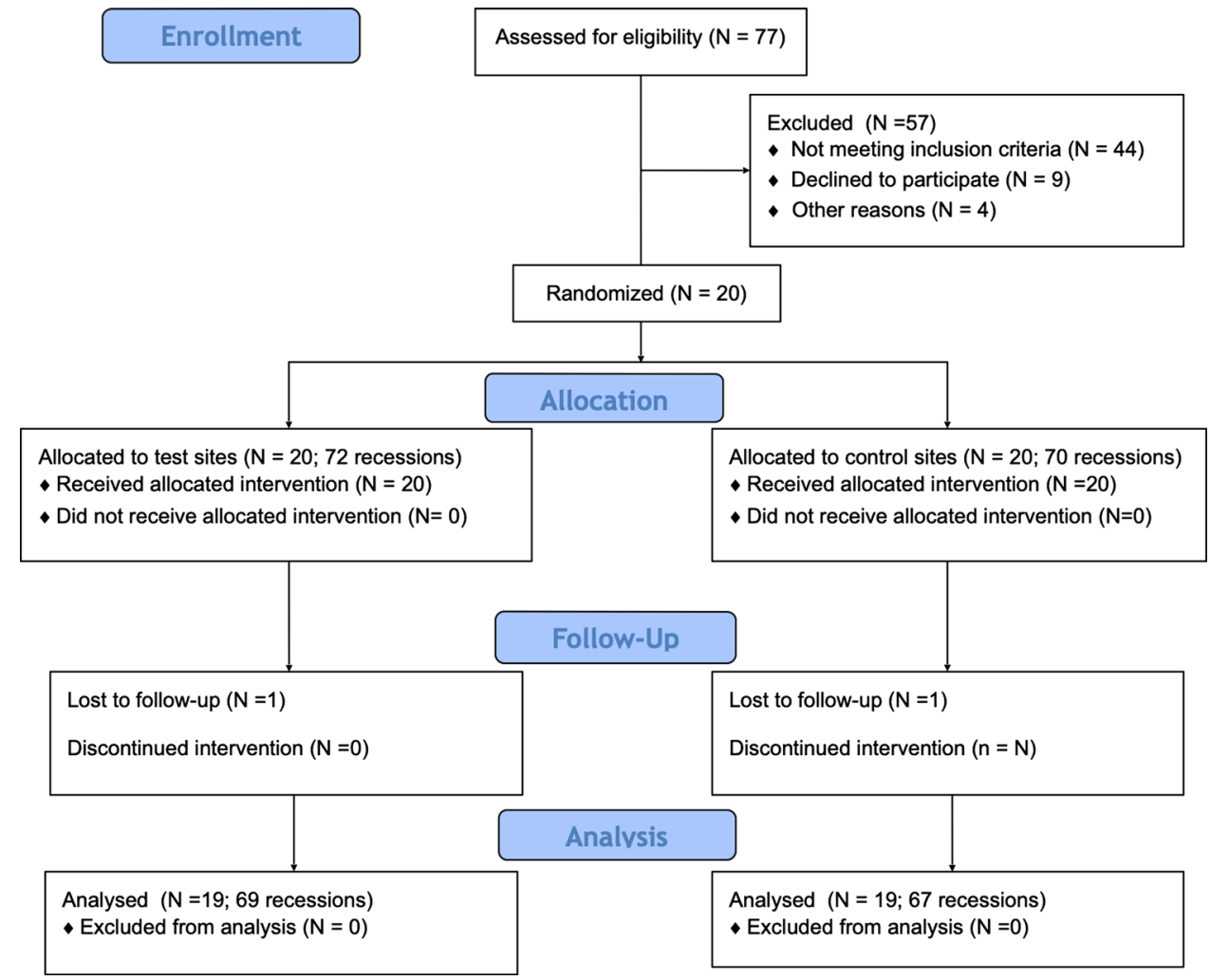

repeated within a difference of $1.0 \mathrm{~mm}$, and an exact agreement was reproduced in $75 \%$ of measurements.

\section{Subject population}

The inclusion criteria were as follows: (1) presence of at least two adjacent gingival recessions type I (RT1: no loss of interproximal attachment) and/or II (RT2: the amount of interproximal attachment loss was less than buccal attachment loss) at least $1 \mathrm{~mm}$ deep on the buccal aspect of homologous maxillary or mandibular teeth, (2) full-mouth plaque score (FMPS) $<20 \%$, (3) full-mouth bleeding on probing $($ FMBOP $)<20 \%$, (5) presence of detectable cemento-enamel junction (CEJ), and (6) age $\geq 18$ years. The following exclusion criteria were established: (1) active periodontal disease, (2) caries lesions or restorations in the cervical area, (3) systemic diseases with compromised healing potential or infectious diseases, (4) use of medications affecting periodontal status, (5) smoking, and (6) pregnancy or lactation.

One examiner (TK) qualified subjects into the study. Each patient signed an informed consent form before enrollment. Once the selected patients agreed to participate in the study, they were provided with detailed oral hygiene instructions on how to use the roll technique with a soft toothbrush. The full-mouth professional tooth cleaning was performed. Twenty patients were enrolled in the study, and one hundred forty-two gingival recessions were treated with MCAT in combination with SCTG either with (test, 72 defects) or without (control, 70 defects) 24\% EDTA.

\section{Primary and secondary outcome variables}

Percentages of root coverage and complete root coverage (ARC, CRC) at 12 months were the primary outcome variables. As secondary outcome variables, reduction in gingival recession height (GR), reduction in recession width (RW), gain in clinical attachment level (CAL), increase in gingival thickness (GT), increase in keratinized tissue width (KTW), root coverage esthetic score (RES) values, and patient-centered outcomes were established.

\section{Clinical measurements}

Clinical parameters were evaluated for each gingival recession before the surgery under local anesthesia by a singleblind examiner (DP) with a graded periodontal probe (UNC probe $15 \mathrm{~mm}$, Hu-Friedy, Chicago, IL, USA) and rounded off to the nearest $0.5 \mathrm{~mm}$. The following parameters were recorded: (1) GR: distance from CEJ to the gingival margin at mid-buccal point of the tooth; (2) RW: horizontal distance measured between the mesial and distal margin of the recession at CEJ level; (3) probing pocket depth (PPD): distance from the gingival margin to the bottom of the gingival sulcus at mid-buccal point of the tooth; (4) clinical attachment 
level (CAL): distance from CEJ to the bottom of the gingival sulcus at mid-buccal point of the tooth; (5) KTW: distance between the gingival margin and the muco-gingival junction (MGJ) in the mid-buccal aspect of the tooth; (6) GT: measured at mid-buccal point of the tooth $3 \mathrm{~mm}$ apical to the gingival margin with the use of endodontic spreader 25 ISO (Poldent, Warsaw, Poland) and a silicon stopper positioned perpendicularly to the gingival surface until the alveolar bone or root surface was reached, an electronic caliper (YATO YT-7201, Toya, Wrocław, Poland), with 0.01-mm accuracy was selected to calculate GT value; (7) FMPS: the percentage of total surfaces (four aspects per tooth) that revealed the presence of plaque [26]; and (8) FMBOP: the percentage of total points (four points per tooth: mesio-buccal, mid-buccal, disto-buccal, mid-lingual) that bled after gentle probing [27].

At 12 months, GR, RW, PPD, CAL, KTW, and GT were again recorded by the same examiner and the percentage of root coverage was measured.

\section{Randomization and allocation concealment}

Randomization had been carried out before surgical treatment by a statistician not involved in the study, using a computerized random number generator. Allocation of treatment sites was concealed in sealed and opaque envelopes, and revealed to the surgeon immediately before procedure. One envelope was opened to designate the surgical site located to the right to one of the two treatment modalities; consequently, the surgical site to the left was treated in accordance with the opposite treatment protocol. No information on treatment allocation was given to the patient.

\section{Surgical treatment}

All surgical procedures were performed by the same surgeon (BG) in line with the modified coronally advanced tunnel technique [6]. Both sides were treated during the same appointment (the right side was always treated first). After local anesthesia with $4 \%$ articaine hydrochloride with adrenaline (1:100,000) (Ubistesin Forte $1.7 \mathrm{ml}$, 3-M ESPE, Saint Paul, MN, USA), the surgical area was prepared as a full-thickness flap up to MGJ and as a split-thickness flap beyond MGJ. The papillary regions were detached in their buccal aspects with the periosteum. The exposed root surfaces were planed using designated curettes (Gracey Curettes, Hu-Friedy). In the next step, SCTG was harvested from the palate using the de-epithelialized graft technique [28]. After removing epithelium, the thickness of SCTG was less than $1 \mathrm{~mm}$, its width was around $4 \mathrm{~mm}$, and its length corresponded with the length of the recipient area. Donor site was covered by a hemostatic sponge which was stabilized with cross-mattress non-resorbable sutures (Seralon
4/0 $18 \mathrm{~mm}$ 3/8, Serag-Wiessner GmbH \& Co. KG, Neila, Germany). In the next step, in case of the test site, the root surfaces were conditioned with 24\% EDTA (PrefGel, Straumann, Basel, Switzerland) for 2 min and washed with saline. SCTG was placed into the tunnel and stabilized at CEJ level with resorbable sling sutures (PGA Resorba 6/0 $11 \mathrm{~mm} 3 / 8$, RESORBA Medical GmBH, Nürnberg, Germany). Subsequently, the buccal flap was advanced coronally to fully cover SCTG and secured with 6/0 non-resorbable monofila-

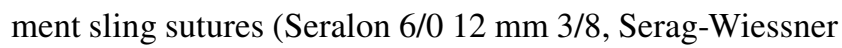
$\mathrm{GmbH} \& \mathrm{Co}$ ). On the control site, the recipient area was prepared in the same manner, but 24\% EDTA was not used.

\section{Post-operative instructions and patient-reported evaluation of morbidity}

After the surgery, patients received $400 \mathrm{mg}$ of ibuprofen and were asked to take the second dose $8 \mathrm{~h}$ later, as well as any additional tablets later on if required. It was suggested that they avoid brushing, flossing, and chewing in the treated area for 2 weeks and rinse the mouth twice daily for 1 min using $0.2 \%$ chlorhexidine solution. Furthermore, patients were provided with a self-report questionnaire to evaluate pain and swelling using visual analog scale (VAS). Each VAS consisted of a horizontal line, $10 \mathrm{~cm}(100 \mathrm{~mm})$ in length, with a statement at each end representing a single extreme of the assessed variable (the scale was anchored by "no pain or swelling" as score 0 and "worst imaginable pain or swelling" as score 100). The questionnaires were self-completed on the 1st, 2nd, 4th, 7th, and 14th days after surgery. Checkup appointments were scheduled for 1,2, and 4 weeks and later at 3, 6, and 12 months, during which plaque control was provided. The sutures were removed 14 days after the surgery and patients were instructed in mechanical tooth cleaning of the operated sides using a soft toothbrush and the roll technique.

\section{Professional esthetic evaluation and patient-reported satisfaction}

The esthetic outcome was assessed post-operatively after 12 months by an independent second examiner (MS), who was blinded to the treatment assignment, in accordance with RES [29]. The evaluation was based on comparing digital photographs taken at baseline and after 12 months. Five variables were assessed: (1) the level of gingival margin (GM); (2) marginal tissue contour (MTC); (3) soft tissue texture (STT); (4) muco-gingival junction alignment (MGJ); and (5) gingival color (GC). A score of 0,3 , or 6 was used for evaluation of GM, whereas a score of $0-1$ was used for each of the other variables. The ideal esthetic score was 10 .

At the 12-month follow-up examination, questionnaires were given to the patients for subjective evaluation of 
esthetics and overall satisfaction. Questions were designed in a dichotomous fashion (yes or no), and VAS was used to evaluate esthetic satisfaction.

\section{Statistical analysis}

Descriptive statistics were performed using mean values, standard deviations (SD), frequencies, and percentages. Normality of distribution for quantitative variables was assessed using the Shapiro-Wilk test. All quantitative variables were normally distributed. Therefore, the Student $t$ test was used to compare means between two treatment groups. Comparison of fractions (percentages) was carried out using Pearson's chi-square test. The following calculations were made: (1) recession reduction $=\mathrm{GR} 0-\mathrm{GR} 12,(2) \mathrm{ARC}=\mathrm{GR} 0-\mathrm{GR} 12 /$ GR0 $\times 100 \%$, (3) CAL gain $=$ CAL0 - CAL 12 , (4) KTW gain $=$ KTW12 - KTW0, and $(5)$ GT gain $=$ GT12 - GT0. The two-way ANOVA was used to determine the difference between treatment groups for patients' VAS-reported pain and swelling on the 1st, 2nd, 4th, and 7th days after the surgery. The analyses were performed using the R 3.2.3 software (R Core Team 2019) and statistical significance was established for $p<0.05$.

\section{Results}

\section{Patient and defect characteristics}

A total of 142 gingival recessions were treated ( 72 defects in the SCTG + EDTA group and 70 defects in the SCTG group). Study teeth were maxillary incisors (30), canines (27), premolars (48), and first molars (10), as well as mandibular canines (6), premolars (17), and first molars (4).
Fifteen subjects had recessions in the maxillary arch, and other five showed defects in the mandibular arch. The majority of treated teeth were upper premolars (Table 1). Baseline data was homogeneous and well-balanced for all of the 20 involved subjects (Table 2).

Healing was uneventful in all patients. One patient was lost before the 12-month follow-up. Consequently, a total of 136 defects were analyzed in 19 subjects 1 year after surgical treatment. The study design and flow are shown in Fig. 1.

\section{Clinical outcomes}

Descriptive statistics for the clinical parameters evaluated at baseline and 12 months after surgery are presented in Table 2. At 12 months, PPD values were not statistically different within and between groups. Significant improvements in GR, RW, and CAL were observed in both groups 12 months post-operatively compared with the baseline measurements, but no statistically significant differences between treatment groups were seen. In the test group, the mean recession height decreased significantly from $1.8 \pm 1.2$ (baseline) to $0.2 \pm 0.7 \mathrm{~mm}$ (12 months), with a percentage of ARC of $86 \pm 31$ and a CRC in 65 out of $72(90.2 \%)$ recession defects. In the control group, mean recession height decreased significantly from $1.0 \pm 1.3$ to $0.2 \pm 0.5 \mathrm{~mm}$, with a percentage of ARC of $84 \pm 30$ and a CRC in 64 out of $70(91.4 \%)$ recession defects. There was also a statistically significant CAL gain in both groups $(1.3 \pm 1.1$ and $1.2 \pm 1.1 \mathrm{~mm}$ for the test and control groups, respectively). Two treatment modalities allowed for a significant gain in KTW and GT on both sites: in case of KTW, from $3.1 \pm 1.6$ to $3.8 \pm 1.2 \mathrm{~mm}$ on the SCTG + EDTA site and from $3.0 \pm 1.3$ to $3.7 \pm 1.3 \mathrm{~mm}$ on the SCTG site; in case of GT, from
Table 1 Characteristics for test and control groups

\begin{tabular}{|c|c|c|c|c|}
\hline \multirow[t]{2}{*}{ Variables } & \multicolumn{2}{|l|}{ Baseline } & \multicolumn{2}{|l|}{12 months } \\
\hline & $\begin{array}{l}\text { SCTG + EDTA } \\
(N=20 ; n=72)\end{array}$ & $\begin{array}{l}\text { SCTG } \\
(N=20 ; n=70)\end{array}$ & $\begin{array}{l}\text { SCTG + EDTA } \\
(N=19 ; n=69)\end{array}$ & $\begin{array}{l}\text { SCTG } \\
\begin{array}{r}(N=19 ; \\
n=67)\end{array}\end{array}$ \\
\hline \multicolumn{5}{|l|}{ Tooth type $(n)$} \\
\hline Incisors & 15 & 15 & 15 & 15 \\
\hline Canines & 17 & 16 & 17 & 16 \\
\hline Premolars & 33 & 32 & 31 & 29 \\
\hline Molars & 7 & 7 & 6 & 6 \\
\hline \multicolumn{5}{|l|}{ Tooth position $(n)$} \\
\hline Maxillary teeth & 57 & 58 & 57 & 55 \\
\hline Mandibular teeth & 15 & 12 & 12 & 12 \\
\hline \multicolumn{5}{|c|}{ Type of GR according to Cairo $(n, \%)$} \\
\hline RT1 & $49(68.06)$ & $47(67.14)$ & - & - \\
\hline RT2 & $23(31.94)$ & $23(32.86)$ & - & - \\
\hline
\end{tabular}

$S C T G$ subepithelial connective tissue graft, $N$ number of patients, $n$ number of defects, $G R$ gingival recession, $R T$ recession type 
Table 2 Clinical parameters (mean and standard deviation) at baseline and 12 months after surgery

\begin{tabular}{|c|c|c|c|}
\hline & Baseline & 12 months & $p$ \\
\hline GR SCTG + EDTA (mm) & $1.80(1.26)$ & $0.26(0.72)$ & $<0.0001 *$ \\
\hline GR SCTG & $1.55(1.34)$ & $0.23(0.59)$ & $<0.0001 *$ \\
\hline$p$ & 0.1376 & 0.7166 & \\
\hline ARC SCTG+EDTA (\%) & & $86.08(31.76)$ & \\
\hline ARC SCTG & & $84.69(30.82)$ & \\
\hline$p$ & & 0.6636 & \\
\hline CRC SCTG + EDTA (\%) & & $65(90.28)$ & \\
\hline CRC SCTG & & $64(91.43)$ & \\
\hline$p$ & & 0.9903 & \\
\hline GR red SCTG + EDTA $(\mathrm{mm})$ & & $1.56(1.18)$ & \\
\hline GR red SCTG & & $1.51(1.35)$ & \\
\hline$p$ & & 0.7547 & \\
\hline RW SCTG + EDTA (mm) & $2.76(1.92)$ & $0.53(1.30)$ & $<0.0001^{*}$ \\
\hline RW SCTG & $2.36(2.05)$ & $0.53(1.29)$ & $<0.0001 *$ \\
\hline$p$ & 0.1264 & 0.9785 & \\
\hline PPD SCTG + EDTA (mm) & $1.42(0.52)$ & $1.58(0.62)$ & 0.0110 \\
\hline PPD SCTG & $1.46(0.57)$ & $1.58(0.70)$ & $0.0093^{*}$ \\
\hline$p$ & 0.5683 & 0.9248 & \\
\hline CAL SCTG + EDTA (mm) & $2.73(1.55)$ & $1.34(1.10)$ & $<0.0001 *$ \\
\hline CAL SCTG & $2.45(1.67)$ & $1.27(1.14)$ & $<0.0001 *$ \\
\hline$p$ & 0.1798 & 0.6711 & \\
\hline $\begin{array}{l}\text { CAL gain SCTG + EDTA } \\
(\mathrm{mm})\end{array}$ & & $1.34(1.10)$ & \\
\hline CAL gain SCTG & & $1.27(1.14)$ & \\
\hline$p$ & & 0.6711 & \\
\hline KTW SCTG + EDTA (mm) & $3.14(1.64)$ & $3.86(1.28)$ & $0.0021 *$ \\
\hline KTW SCTG & $3.00(1.36)$ & $3.76(1.33)$ & $<0.0001 *$ \\
\hline$p$ & 0.4727 & 0.6000 & \\
\hline $\begin{array}{l}\text { KTW gain SCTG + EDTA } \\
(\mathrm{mm})\end{array}$ & & $0.78(1.18)$ & \\
\hline KTW gain SCTG & & $0.79(1.00)$ & \\
\hline$p$ & & 0.2690 & \\
\hline GT SCTG + EDTA (mm) & $1.33(0.47)$ & $1.93(0.63)$ & $<0.0001^{*}$ \\
\hline GT SCTG & $1.25(0.33)$ & $1.81(0.52)$ & $<0.0001^{*}$ \\
\hline$p$ & 0.0545 & 0.3166 & \\
\hline $\begin{array}{l}\text { GT gain SCTG + EDTA } \\
(\mathrm{mm})\end{array}$ & & $0.61(0.51)$ & \\
\hline GT gain SCTG & & $0.52(0.49)$ & \\
\hline$p$ & & 0.3166 & \\
\hline
\end{tabular}

$G R$ gingival recession height, $S C T G$ subepithelial connective tissue graft, $A R C$ average root coverage, $C R C$ complete root coverage, $G R$ red gingival recession reduction, $R W$ gingival recession width, $P P D$ probing pocket depth, $C A L$ clinical attachment level, $K T W$ keratinized tissue width, $G T$ gingival thickness. *Statistically significant $(p \leq 0.05)$

$1.3 \pm 0.4$ to $1.9 \pm 0.6$ on the SCTG + EDTA site and from $1.2 \pm 0.3$ to $1.8 \pm 0.5 \mathrm{~mm}$ on the SCTG site. No significant differences with respect to CAL gain, WKT gain, and GT gain at 12 months between two study groups were found.

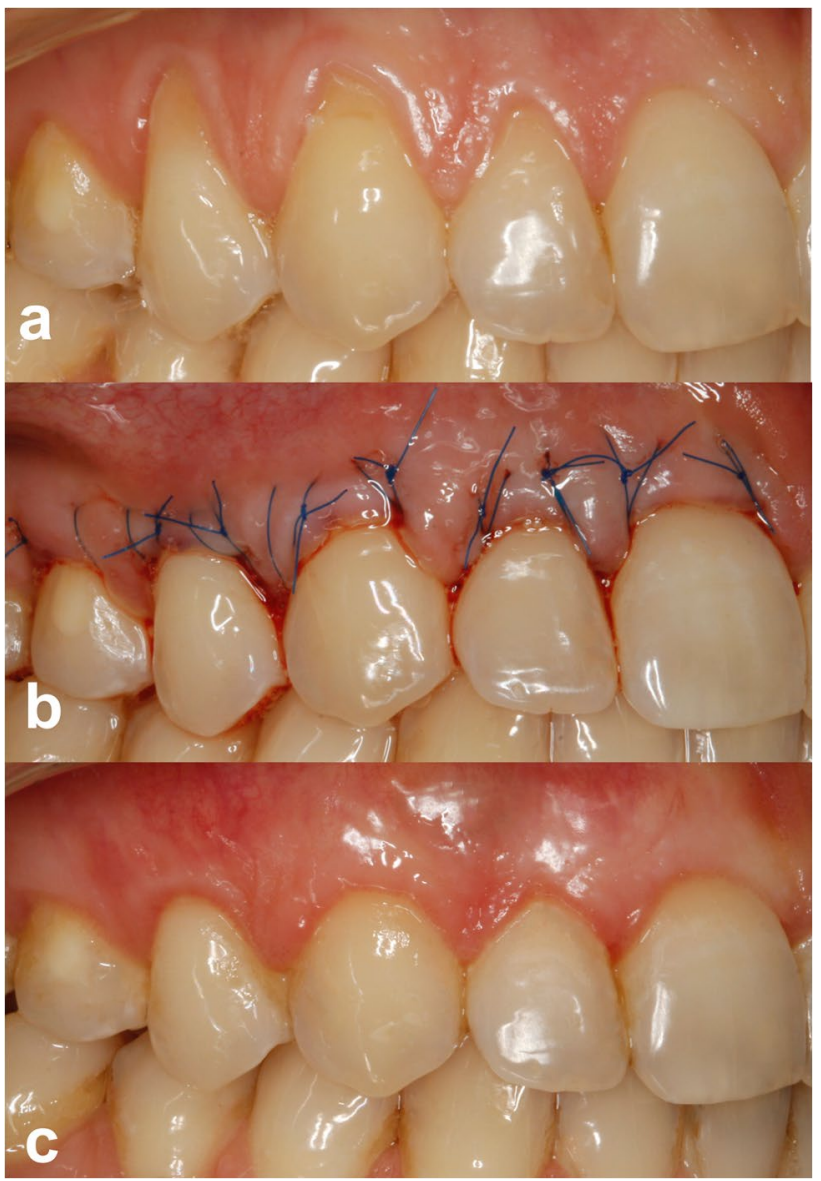

Fig. 2 a Pre-operative view of gingival recessions on test side. b Immediate post-operative view. c 12-month post-operative view

Clinical outcomes of one of the patients are shown in Fig. 2 and Fig. 3.

\section{Professional esthetic evaluation}

Both treatments showed high esthetic results. The root coverage esthetic score in the SCTG + EDTA group was $8.9 \pm 1.3$, whereas in the SCTG group $8.7 \pm 1.3(p=0.3358)$ (Table 3$)$. No statistically significant differences in assessed parameters of RES between the two treatment modalities were found. Keloid formation was not observed in any patient after 12 months.

\section{Patient-reported outcome measures}

The values on the post-operative VAS are presented in Table 4. Slight pain was reported on 14 (70\%) test sites and on 17 (85\%) control sites. Greater pain intensity was reported on the 1st and 2nd days after surgery. By day 14, no pain was recorded for any of the patients. Slight to moderate swelling occurred in $18(90 \%)$ subjects at day 1 post-surgery, 


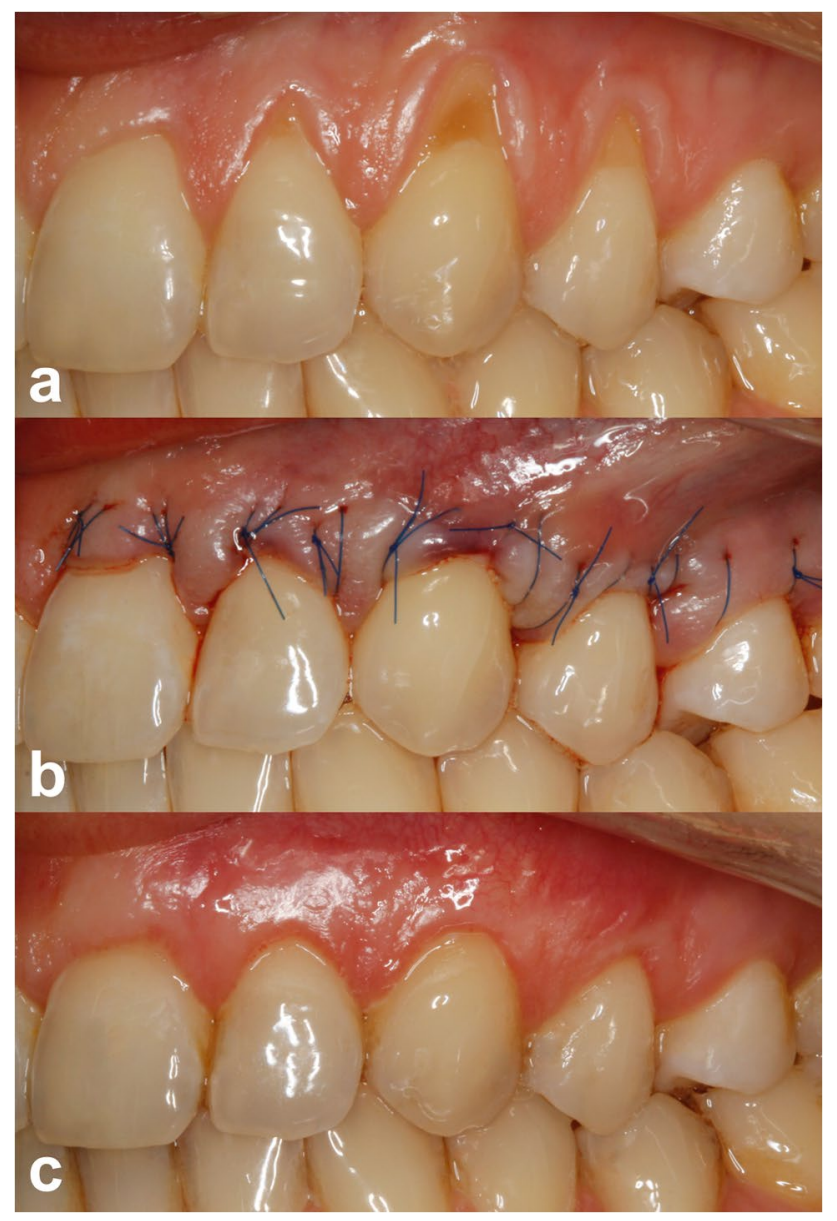

Fig. 3 a Pre-operative view of gingival recessions on control side. $\mathbf{b}$ Immediate post-operative view. c 12-month post-operative view

and in $7(35 \%)$ patients at day 7 . By day 14, no edema was reported for any of the patients. There were no statistically significant differences in terms of pain or edema experience between two sites.

Table 5 depicts the evaluation of esthetics and overall satisfaction by patients. No significant difference was detected between both sites with respect to gingival color, gingival contour, and gingival recession coverage, as measured by VAS values. When comparing treatment modalities, VAS assessments for overall patient satisfaction were generally high with nearly identical mean values of $78.9 \pm 23.1$ for the test site and of $84.7 \pm 13.9$ for the control site. Almost all patients declared a willingness to participate in the treatment again, and would recommend it to others.

\section{Discussion}

The effect of EDTA root surface conditioning to improve outcomes of root coverage of multiple RT1 and RT2 gingival recessions with MCAT + SCTG remains unknown. To the best of our knowledge, this is the first study that evaluates the efficacy of 24\% EDTA root treatment when the surgery is performed with modified coronally advanced tunnel and subepithelial connective tissue graft. Being as it may, the present investigation may add relevant information to the existing literature. At 12 months, ARC was $86.0 \%$ for SCTG-EDTA-treated defects and $84.6 \%$ for SCTG-treated defects. CRC was found in $90.2 \%$ (tests) and $91.4 \%$ (controls) of the cases. KTW gain was $0.78 \mathrm{~mm}$ on sites where roots were conditioned with EDTA, and $0.79 \mathrm{~mm}$ on sites without EDTA, whereas GT gain reached 0.61 and 0.52 , respectively. However, complete root coverage is not the sole goal of treatment and final soft tissue quality, such as gingival margin contour, color, and texture, and lack of scar tissue formation are of utmost importance when root coverage procedures are evaluated. In the present study, the professional esthetic assessment carried out using RES revealed very high scores in terms of both tests (8.9) and controls (8.7). In this respect, reported outcomes are in agreement with those published in previous studies, where MCAT was applied [7, 30-32], and remain consistent with the conclusion of a recent systematic reviews and meta-analyses [15, 33]. Be that as it may, test and control sites presented similar outcomes related to root coverage and periodontal and esthetic parameters, with no statistical differences between them. Unfortunately, it is impossible to make direct comparisons with other studies due to lack of trials that would adapt a similar approach. Therefore, based on the findings presented in the current research, root surface modification with $24 \%$ EDTA provided no additional benefit 12 months after root coverage with MCAT + SCTG in terms of clinical and esthetic parameters. However, the question remains whether EDTA application may influence the stability of reported outcomes of surgical treatment in the longer term.
Table 3 Evaluation of esthetic outcomes after 12 months (mean and standard deviation)

\begin{tabular}{lllllll}
\hline & GM & MTC & STT & MGJ & GC & RES \\
\hline SCTG+EDTA & $5.51(1.12)$ & $0.87(0.34)$ & $0.86(0.35)$ & $0.88(0.33)$ & $0.91(0.28)$ & $8.98(1.30)$ \\
SCTG & $5.47(1.15)$ & $0.80(0.40)$ & $0.83(0.38)$ & $0.86(0.35)$ & $0.87(0.34)$ & $8.79(1.31)$ \\
$p$ & 0.8447 & 0.2234 & 0.5464 & 0.6636 & 0.3461 & 0.3358 \\
\hline
\end{tabular}

SCTG subepithelial connective tissue graft, GM gingival margin, MTC marginal tissue contour, STT soft tissue texture, $M G J$ muco-gingival junction alignment, $G C$ gingival color, $R E S$ root coverage esthetic score 


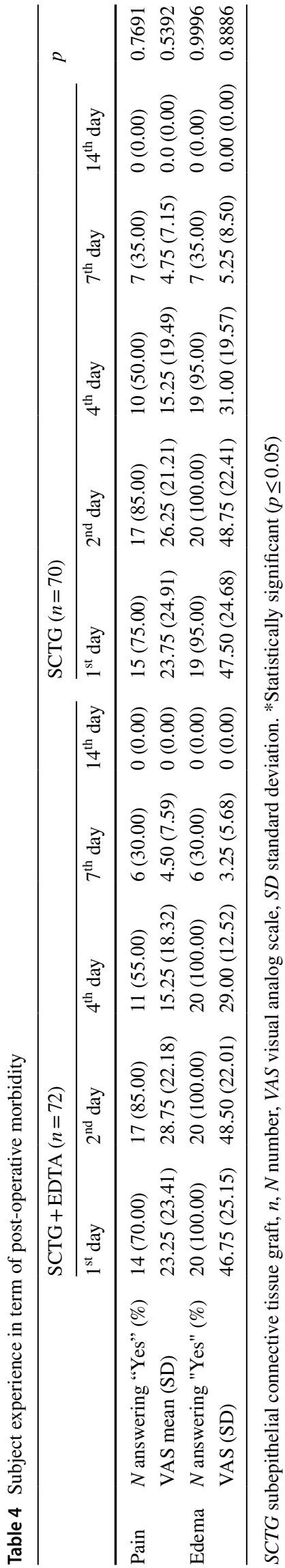

The healing of SCTG to the root surface demonstrated that the connection between the graft and the root was largely consisted of a combination of long junctional epithelium and connective tissue attachment, with fibers parallel to the root surface [34]. The use of root modifiers has been proposed by some authors in an attempt to enhance the success rate of root coverage by means of favoring attachment of the regenerated periodontal structures to the root surface. For instance, enamel matrix derivative showed the potential to promote substantial formation of the periodontal attachment apparatus on tooth roots with new bone, cementum, and periodontal ligament, as well as new attachment formation (connective tissue adhesion) [35, 36]. In this matter, more stable attachment showed less recession rebound and better coverage after 2 years [37]. By the same token, EDTA was found to remove the smear layer, expose collagen fibers, and enhance early cell colonization [38]. After conditioning with EDTA, root surface became a more biocompatible environment for attachment, growth, migration, proliferation, and differentiation of periodontal ligament cells under in vitro conditions [39]. In another in vitro study, EDTA alone or in combination with enamel matrix protein promoted enlargement, proliferation, and density of fibroblast [40]. It was also assumed that root conditioning might stabilize the bond between the fibrin of the blood clot and the root surface in the early healing process [41]. A clinical repair with fiber attachment would provide preferable functional permanence compared with long junctional epithelium [42]. Furthermore, it would grant stability of clinical attachment gain in the long term and boost reconstructive treatment goals. However, due to ethical concerns, it is impossible to evaluate the histological healing pattern between the root surface and SCTG and to determine the type of attachment achieved in clinical settings.

Very recent systematic review and meta-analysis revealed that adjunct application of EDTA may provide benefits when performing root coverage treatment with coronally advanced flap (CAF) + SCTG [22]. The authors reported statistically significant differences for GR reduction $(3.68 \mathrm{~mm}$ versus $3.07 \mathrm{~mm})$, CAL gain $(4.15 \mathrm{~mm}$ versus $3.07 \mathrm{~mm})$, and PD changes $(-0.44 \mathrm{~mm}$ versus $0.27 \mathrm{~mm})$ in favor of the EDTA group. The outcomes of CRC and KTW gain were not significantly different. A possible explanation might be attributed to the several advantages of the CAF approach, especially increased access to root surface area in case of vertical releasing incision preparation, which also facilitates periosteal dissection [43]. These results are in contrast with our study, in which root conditioning with 24\% EDTA did not seem to influence 12-month clinical outcomes since the abovementioned differences were not statistically significant between tests and controls. Reasons for this are open to speculation, but it might be associated with different surgical approaches used. One reasonable hypothesis may be related 
Table 5 Results of patient questionnaire for evaluation of esthetics and overall satisfaction

\begin{tabular}{|c|c|c|c|c|c|}
\hline \multirow[t]{2}{*}{ Question } & \multicolumn{2}{|c|}{ SCTG + EDTA $(n=72)$} & \multicolumn{2}{|c|}{$\operatorname{SCTG}(n=70)$} & \multirow[t]{2}{*}{$p$} \\
\hline & $\begin{array}{l}N \text { answering } \\
\text { "Yes" (\%) }\end{array}$ & VAS mean (SD) & $\begin{array}{l}N \text { answering } \\
\text { "Yes" (\%) }\end{array}$ & VAS mean (SD) & \\
\hline Gingival color & $20(100 \%)$ & $83.23(13.35)$ & $20(100 \%)$ & $82.11(12.09)$ & 0.8536 \\
\hline Gingival contour & $19(95 \%)$ & $81.89(14.90)$ & $19(95 \%)$ & $81.17(13.43)$ & 0.9999 \\
\hline Recession coverage & $19(95 \%)$ & $75.01(19.57)$ & $19(95 \%)$ & $79.44(14.83)$ & 0.4079 \\
\hline "How satisfied are you with the results of the surgery?" & $18(90 \%)$ & $78.89(23.11)$ & $19(95 \%)$ & $84.69(13.89)$ & 0.9982 \\
\hline "Would you decide again to go for the treatment performed?" & $18(90 \%)$ & $81.33(16.61)$ & $18(90 \%)$ & $81.94(16.59)$ & 0.9091 \\
\hline "Would you recommend the treatment to another person?" & $18(90 \%)$ & $77.49(16.74)$ & $19(95 \%)$ & $83.84(14.67)$ & 0.9982 \\
\hline
\end{tabular}

$S C T G$ subepithelial connective tissue graft, $n, N$ number, $V A S$ visual analog scale, $S D$ standard deviation. * Statistically significant $(p \leq 0.05)$

to the flap design. Without vertical releasing incisions and under application of a split-full-split flap preparation in MCAT, the flap is not fully detached from the underlying bone, papillae maintain their integrity, and root surfaces are not easily accessible, which is why the probability of contamination of root surface with blood or saliva is higher. Consequently, this may alter the effect of root modification and conditioning with 24\% EDTA and decrease its potential accordingly. Similar conclusions on feasible limitations of flap design in root conditioning were drawn by Stähli et al. [31] who investigated the beneficial influence of enamel matrix derivative on clinical results using enamel matrix derivatives following treatment of single and multiple GR by the MCAT+SCTG. Quite interestingly, in another recent study, root conditioning before root coverage with a partialthickness double-pedicle graft did not significantly affect the outcome [23].

With respect to patient-reported outcomes regarding early post-operative morbidity, as well as long-term esthetics and satisfaction, little research has been carried out on MCAT and none of hitherto existing studies evaluated the impact of additional root conditioning with 24\% EDTA on this matter. In the present study, pain and swelling were reported by the majority of patients 1 day after the surgery and gradually decreased during the first week. The maximum severity of pain and edema was reported on the second day. No major adverse events were reported or observed. Mean intensity of pain described was low, whereas swelling intensity could be categorized as low or moderate. Two days after the surgery, mean VAS score was 28.7 in terms of pain and 48.5 in terms of swelling for the SCTG + EDTA sites, and 26.2 and 48.7 for the SCTG sites, respectively. No statistically significant differences were observed in the severity of early post-operative pain and swelling between sites treated with or without EDTA. It can be hypothesized that the extension and split preparation of flap itself may have negatively contributed to the patients' early post-operative perception. Moreover, recent review and network meta-analysis concluded that SCTG-based techniques significantly increase patient morbidity compared to flap alone [33]. The present results compare well with those of previous studies that interpreted early post-operative patient-reported discomfort following treatment of GR with MCAT [31, 32]. With reference to the patients' esthetic satisfaction, 12-month VAS value evaluated in the questionnaires for the SCTG + EDTA group was 78.9, whereas for the SCTG group 84.7 ( $p=0.9982)$. Quite similarly, equally favorable results were also reported for both treatment modalities in terms of subjective perception of gingival color and marginal contour. All in all, the overall patient esthetic satisfaction was high. A total of 18 patients stated that they were willing to undergo further periodontal surgery if required. Generally speaking, 24\% EDTA root conditioning prior to root coverage procedures with MCAT did not significantly affect patient-reported outcomes in the current study. The findings of our research are consistent with results of our previous study [32] and are slightly inferior to the outcomes presented by Zuhr et al. [44], who reported VAS values of 92.1 for tunnel-treated GR. One reason for discrepancy could be the fact that in the aforementioned study both single and multiple recessions were treated.

The current study has some limitations that should be addressed. The first is relatively short time-period of assessment, as the evaluation of clinical parameters should be performed in the medium to long term [45]. The second is the lack of histological evaluation of healing pattern; however, this was impossible for ethical reasons. Therefore, no comments could be made on the type of attachment and tissues formed. Last but not least, it should also be stated that results obtained in terms of GR coverage were affected by the strict inclusion criteria and by careful patient selection. The outcomes may have been different if the entry criteria had been modified. Furthermore, in vivo studies and prospective randomized studies with larger sample size and longer follow-ups are required to investigate the influence of root conditioning with 24\% EDTA in the healing process after root coverage procedures, and to evaluate the long-term stability of clinical outcomes. Different types of gingival recessions defects 
in all types of teeth should be thoroughly investigated in future studies.

\section{Conclusions}

Considering the limitations of the present study, it may be concluded that.

- MCAT+SCTG is an extremely effective plastic approach in treating multiple GR defects,

- The use of 24\% EDTA for root conditioning did not affect 12-month clinical and esthetic outcomes in GR treatment with MCAT and SCTG,

- Patient-reported outcomes were not related to root surface conditioning with $24 \%$ EDTA,

- We have not found any evidence to support root conditioning with $24 \%$ EDTA prior to root coverage of multiple RT1 and RT2 gingival recessions with $\mathrm{MCAT}+\mathrm{SCTG}$.

\section{Declarations}

Ethics approval All procedures performed in studies involving human participants were in accordance with the ethical standards of the institutional and/or national research committee and with the 1964 Helsinki declaration and its later amendments or comparable ethical standards. This study was reviewed and approved by the Bioethics Committee of Medical University of Warsaw, Poland (KB/208/2017). An informed consent was obtained from all individual participants included in the study.

Open Access This article is licensed under the Creative Commons Attribution 4.0 International License, which permits use, sharing, adaptation, distribution and reproduction in any medium or format, as long as you give appropriate credit to the original author(s) and the source, provide a link to the Creative Commons license, and indicate if changes were made. The images or another third party material in this article are included in the article's Creative Commons licence, unless indicated otherwise in a credit line to the material. If material is not included in the article's Creative Commons license and your intended use is not permitted by statutory regulation or exceeds the permitted use, you will need to obtain permission directly from the copyright holder. To view a copy of this license, visit http://creativecommons. org/licenses/by/4.0/.

Open Access This article is licensed under a Creative Commons Attribution 4.0 International License, which permits use, sharing, adaptation, distribution and reproduction in any medium or format, as long as you give appropriate credit to the original author(s) and the source, provide a link to the Creative Commons licence, and indicate if changes were made. The images or other third party material in this article are included in the article's Creative Commons licence, unless indicated otherwise in a credit line to the material. If material is not included in the article's Creative Commons licence and your intended use is not permitted by statutory regulation or exceeds the permitted use, you will need to obtain permission directly from the copyright holder. To view a copy of this licence, visit http://creativecommons.org/licenses/by/4.0/.

\section{References}

1. Rios FS, Costa RSA, Wagner TP, Christofoli BR, Goergen J, Izquierdo C, Jardim JJ, Maltz M, Haas AN (2021) Incidence and progression of gingival recession over 4 years: a population-based longitudinal study. J Clin Periodontol 48(1):112-125. https://doi. org/10.1111/jcpe. 13383

2. Rios FS, Costa RS, Moura MS, Jardim JJ, Maltz M, Haas AN (2014) Estimates and multivariable risk assessment of gingival recession in the population of adults from Porto Alegre. Brazil J Clin Periodontol 41(11):1098-1107. https://doi.org/10.1111/jcpe. 12303

3. Romandini M, Soldini MC, Montero E, Sanz M (2020) Epidemiology of mid-buccal gingival recessions in NHANES according to the 2018 World Workshop Classification System. J Clin Periodontol 47(10):1180-1190. https://doi.org/10.1111/jcpe.13353

4. Zabalegui I, Sicilia A, Cambra J, Gil J, Sanz M (1999) Treatment of multiple adjacent gingival recessions with the tunnel subepithelial connective tissue graft: a clinical report. Int J Periodontics Restorative Dent 19(2):199-206

5. Zuhr O, Rebele SF, Cheung SL, Hürzeler MB (2018) Research Group on Oral Soft Tissue Biology and Wound Healing. Surgery without papilla incision: tunneling flap procedures in plastic periodontal and implant surgery. Periodontol. 77(1):123-149. https:// doi.org/10.1111/prd.12214

6. Zuhr O, Fickl S, Wachtel H, BolzW HürzelerMB (2007) Covering of gingival recessions with a modified microsurgical tunnel technique: case report. Int J Periodontics Restorative Dent 27(5):457-463

7. Aroca S, Keglevich T, Nikolidakis D, Gera I, Nagy K, Azzi R, Etienne D (2010) Treatment of class III multiple gingival recessions: a randomized-clinical trial. J Clin Periodontol 37(1):88-97. https://doi.org/10.1111/j.1600-051X.2009.01492.x

8. Aroca S, Molnar B, Windisch P, Gera I, Salvi GE, Nikolidakis D, Sculean A (2013) Treatment of multiple adjacent Miller class I and II gingival recessions with a modified coronally advanced tunnel (MCAT) technique and a collagen matrix or palatal connective tissue graft: a randomized, controlled clinical trial. J Clin Periodontol 40(7):713-720. https://doi.org/10.1111/jcpe.12112

9. Bakhishov H, Isler SC, Bozyel B, Yildirim B, Tekindal MA, Ozdemir B (2021) De-epithelialized gingival graft versus subepithelial connective tissue graft in the treatment of multiple adjacent gingival recessions using the tunnel technique: 1-year results of a randomized clinical trial. J Clin Periodontol 48(7):970-983. https://doi.org/10.1111/jcpe.13452

10. Cieślik-Wegemund M, Wierucka-Młynarczyk B, Tanasiewicz M, Gilowski $Ł$ (2016) Tunnel technique with collagen matrix compared with connective tissue graft for treatment of periodontal recession: a randomized clinical trial. J Periodontol 87(12):14361443. https://doi.org/10.1902/jop.2016.150676

11. Sculean A, Cosgarea R, Stähli A, Katsaros C, Arweiler NB, Brecx M, Deppe H (2014) The modified coronally advanced tunnel combined with enamel matrix derivative and subepithelial connective tissue graft for the treatment of isolated mandibular Miller I and II gingival recessions: a report of 16 cases. Quintessence Int (Berl) 45(10):829-835. https://doi.org/10.3290/j.qi.a32636

12. Korkmaz B, Balli U (2021) Clinical evaluation of the treatment of multiple gingival recessions with connective tissue graft or concentrated growth factor using tunnel technique: a randomized 
controlled clinical trial. Clin Oral Investig 2021 Apr 8. https://doi. org/10.1007/s00784-021-03935-3. Online ahead of print

13. Novaes AB Jr (2000) Palioto DB (2019) Experimental and clinical studies on plastic periodontal procedures. Periodontol 79(1):5680. https://doi.org/10.1111/prd.12247

14. Aroca S, Di Domenico GL, Darnaud C, de Sanctis M (2021) Modified coronally advanced tunnel technique with site-specific application of connective tissue graft for the treatment of multiple adjacent maxillary gingival recessions: a case series. Int $\mathrm{J}$ Periodontics Restorative Dent 41 (2): 253-259. https://doi.org/10. 11607/prd.4836

15. Tavelli L, Barootchi S, Nguyen TVN, Tattan M, Ravidà W-L (2018) Efficacy of tunnel technique in the treatment of localized and multiple gingival recessions: a systematic review and metaanalysis. J Periodontol 89(9):1075-1090. https://doi.org/10.1002/ jper.18-0066

16. Mounssif I, Stefanini M, Mazzotti C, Marzadori M, Sangiorgi M (2000) Zucchelli G (2018) Esthetic evaluation and patientcentered outcomes in root-coverage procedures. Periodontol 77(1):19-53. https://doi.org/10.1111/prd.12216

17. de Sanctis M, Clementini M (2014) Flap approaches in plastic periodontal and implant surgery: critical elements in design and execution. J Clin Periodontol 41(Suppl 15):S108-S122. https:// doi.org/10.1111/jcpe.12189

18. Zucchelli G, Mounsiff I, Stefanini M, Mele M, Montebugnoli L, Sforza NM (2009) Hand and ultrasonic instrumentation in combination with root-coverage surgery: a comparative controlled randomized clinical trial. J Periodontol 80(4):577-585. https:// doi.org/10.1902/jop.2009.080485

19. Cavassim R, Leite FRM, Zandim DL, Dantas AAR, Sampaio JEC (2010) Smear layer removal for collagen fiber exposure after citric acid conditionings. J Contemp Dent Pract 11(6):E001-E008

20. Jalaluddin M, Ramanna PK, Ar Naseema D, Alshahrani MA, Kumari V, Atom J (2020) Impact of different root conditioning agents on periodontally affected root surface: a scanning electron microscope study. J Contemp Dent Pract 21(8):863-867

21. Mariotti A (2003) Efficacy of chemical root surface modifiers in the treatment of periodontal disease. A systematic review Ann Periodontol 8(1):205-226. https://doi.org/10.1902/annals.2003.8. 1.205

22. Barootchi S, Tavelli L, Ravidà A, Wang C-W, Wang H-L (2018) Effect of EDTA root conditioning on the outcome of coronally advanced flap with connective tissue graft: a systematic review and meta-analysis. Clin Oral Investig 22(8):2727-2741. https:// doi.org/10.1007/s00784-018-2635-3

23. Sebaoun A, Meir H, Slutzkey GS, Nemcovsky CE, Beitlitum I (2021) Effect of root surface conditioning on gingival recession coverage with a connective tissue graft. A retrospective comparative study of three different agents. J Esthet Restor Dent $2021 \mathrm{Apr}$ 5. https://doi.org/10.1111/jerd.12730. Online ahead of print

24. Chambrone L, de Castro Pinto RCN (2000) Chambrone LA (2019) The concepts of evidence-based periodontal plastic surgery: application of the principles of evidence-based dentistry for the treatment of recession-type defects. Periodontol 79(1):81-106. https:// doi.org/10.1111/prd.12248

25. Julious SA, Campbell MJ (1998) Sample size calculations for paired or matched ordinal data. Stat Med 17(14):1635-1642. https://doi.org/10.1002/(sici)1097-0258(19980730)17:14\%3c163 5::aid-sim881\%3e3.0.co;2-k

26. O'Leary TJ, Drake RB, Naylor JE (1972) The plaque control record. J Periodontol 43(1):38-46

27. Ainamo J, Bay I (1975) Problems and proposals for recording gingivitis and plaque. Int Dent J 25:229-235

28. Zucchelli G, Mele M, Stefanini M, Mazzotti C, Marzadori M, Montebugnoli L, de Sanctis M (2010) Patient morbidity and root coverage outcome after subepithelial connective tissue and deepithelialized grafts: a comparative randomized controlled clinical trial. J Clin Periodontol 37(80):728-738. https://doi.org/ 10.1111/j.1600-051X,2010.01550.x

29. Cairo F, Rotundo R, Miller PD, Pini Prato G (2009) Root coverage esthetic score: a system to evaluate the esthetic outcome of the treatment of gingival recession through evaluation of clinical cases. J Periodontol 80(4):705-710. https://doi.org/10.1902/jop. 20009.080565

30. Aroca S, Barbier A, Clementini M, Renouard F, de Sanctis M (2018) Treatment of class III multiple gingival recessions: prognostic factors for achieving a complete root coverage. J Clin Periodontol 45(7):861-868. https://doi.org/10.1111/jcpe.12923

31. Stähli A, Imber J-C, Raptis E, Salvi GE, Eick S, Sculean A (2020) Effect of enamel matrix derivative on wound healing following gingival recession coverage using the modified coronally advanced tunnel and subepithelial connective tissue graft: a randomised, controlled, clinical study. Clin Oral Invest 24(2):1043-1051. https://doi.org/10.1007/s00784-019-03008-6

32. Górski B, Górska R, Wysokińska-Miszczuk J, Kaczyński T (2020) Tunnel technique with enamel matrix derivative in addition to subepithelial connective tissue graft compared with connective tissue graft alone for the treatment of multiple gingival recessions: a randomized clinical trial. Clin Oral Invest 24(12):4475-4486. https://doi.org/10.1007/s00784-03312-6

33. Cairo F, Barootchi S, Tavelli L, Barbato L, Wang H-L, Rasperini G, Graziani F, Tonetti M (2020) Aesthetic- and patientrelated outcomes following root coverage procedures: a systematic review and network meta-analysis. J Clin Periodontol 47(11):1403-1415. https://doi.org/10.1111/jcpe.13346

34. Guiha R, el Khodeiry S, Mota L, Caffesse R (2001) Histological evaluation of healing and revascularization of the subepithelial connective tissue graft. J Periodontol 72(4):470-478. https:// doi.org/10.1902/jop.2001.72.4.470

35 Yukna RA, Mellonig JT (2000) Histologic evaluation of periodontal healing in humans following regenerative therapy with enamel matrix derivative. A 10 -year case series. J Periodontol 71(5):752-759. https://doi.org/10.1902/jop.2000.71.5.752

36. McGuire MK, Scheyer ET, Schupbach P (2016) A prospective, case-controlled study evaluating the use of enamel matrix derivative on human buccal recession defects: a human histologic examination. J Periodontol 87(6):645-653. https://doi.org/10. 1902/jop.2016.150459

37. Spahr A, Haegewald S, Tsoulfidou F, Rompola E, Heijl L, Bernimoulin JP, Ring C, Sander S, Haller B (2005) Coverage of Miller class I and class II recession defects using enamel matrix proteins versus coronally advanced flap technique: a 2-year report. J Periodontol 76(11):1871-1880. https://doi.org/ 10.1902/jop.2005.76.11.1871

38. Blomlöf J, Blomlöf L, Lindskog S (1997) Effect of different concentrations of EDTA on smear layer removal and collagen exposure in periodontitis-affected root surfaces. J Clin Periodontol 24(8):534-537. https://doi.org/10.1111/j.1600-051x. 1997.tb00225.x

39. Zhan X, Yan W, Yan J, Tong W, Chen W, Lin Y (2021) LPCGF and EDTA conditioning of the root surface promotes the adhesion, growth, migration and differentiation of periodontal ligament cells. J Periodontol 92(5):738-747. https://doi.org/10. 1002/JPER.20-0103

40. Kasaj A, Klein MO, Dupont J, Willershausen B, Krahn U, Gotz H, Zeiler J, Brullmann D, Duschner H (2013) Early root surface colonization by human periodontal ligament fibroblasts following treatment with different biomaterials. Acta Odontol Scand 71(6):1579-1587. https://doi.org/10.3109/00016357.2013. 777115

41. Gamal AY, Abdel-Ghaffar KA, Zouair MG, Salama MH, Destawy MTE (2018) Dimensional evaluation of blood clot gap distances 
within the intrabony defects following grafting and EDTA root surface treatment- experimental study in dogs. J Periodontol 89(6):691-698. https://doi.org/10.1002/JPER.17-0361

42. Karam PSBH, Sant'Ana ACP, de Rezende MLR, Greghi SLA, Samante CA, Zangrando MSR (2016) Root surface modifiers and subepithelial connective tissue graft for treatment of gingival recessions: a systematic review. J Periodont Res 51(2):175-185. https://doi.org/10.1111/jre.12296

43. Santamaria MP, Neves F, Silveira CA, Connective tissue graft and tunnel or trapezoidal flap for the treatment of single maxillary gingival recessions: a randomized clinical trial. J Clin Periodontol 44 (5): 540-547. https://doi.org/10.1111/jcpe.12714

44. Zuhr O, Bäumer D, Hürzeler M (2014) The addition of soft tissue replacement grafts in plastic periodontal and implant surgery: critical elements in design and execution. J Clin Periodontol 41(Suppl 15):123-142. https://doi.org/10.1111/jcpe.12185

45. Agudio G, Nieri M, Rotundo R, Franceschi D, Cortellini P, Pini Prato GP (2009) Periodontal conditions of sites treated with gingival-augmentation surgery compared to untreated contralateral homologous sites: a 10- to 27-year long-term study. J Periodontol 80(9):1399-1405. https://doi.org/10.1902/jop.2009.090122

Publisher's Note Springer Nature remains neutral with regard to jurisdictional claims in published maps and institutional affiliations. 